IP Periodica Polytechnica Civil Engineering

\author{
62(4), pp. 858-865, 2018 \\ https://doi.org/10.3311/PPci.11928 \\ Creative Commons Attribution (i)
}

RESEARCH ARTICLE

\section{Using Artificial Neural Networks Approach to Estimate Compressive Strength for Rubberized Concrete}

\author{
Rahali Bachir $^{1 *}$, Aissa Mamoune Sidi Mohammed ${ }^{2}$, Trouzine Habib ${ }^{1}$
}

Received 05 January 2018; Revised 21 March 2018; Accepted 27 March 2018

\begin{abstract}
Artificial neural network (ANN) is a soft computing technique that has been used to predict with accuracy compressive strength known for its high variability of values. ANN is used to develop a model that can predict compressive strength of rubberized concrete where natural aggregate such as fine and coarse aggregate are replaced by crumb rubber and tire chips. The main idea in this study is to build a model using ANN with three parameters that are: water/cement ratio, Superplasticizer, granular squeleton. Furthermore, the data used in the model has been taken from various literatures and are arranged in a format of three input parameters: water/ cement ratio, superplasticizer, granular squeleton that gathers fine aggregates, coarse aggregates, crumb rubber, tire chips and output parameter which is compressive strength. The performance of the model has been judged by using correlation coefficient, mean square error, mean absolute error and adopted as the comparative measures against the experimental results obtained from literature. The results indicate that artificial neural network has the ability to predict compressive strength of rubberized concrete with an acceptable degree of accuracy using new parameters.
\end{abstract}

\section{Keywords}

concrete, compressive strength, rubber, neural network, prediction

\footnotetext{
1 Department of Civil Engineering and Public Works,

Faculty of Technology,

Sidi Bel Abbes University

BP 89 22000, Algeria

2 Smart Structures Laboratory (SSL),

University Ctr of Ain Temouchent,

Po Box 284, 46000, Algeria

* Corresponding author, email: rahalibachir@gmail.com
}

\section{Introduction}

Normally, waste tires are considered a serious pollution problem because the waste rubber is not easily bio-degradable even after a long period landfill treatment [1-7]. During the last decades, several tentative strategies have been conducted to investigate the potential reuse of the recycled waste-tires as an innovative technique and to recycle them in civil engineering application [1-8]. Therefore, the addition of rubber into concrete makes that concrete regarded as a lightweight material. The literature about the use of tire rubber particles in cement-based materials focuses on the use of tire rubber as an aggregate in concrete such as ground, crumb and chipped rubber. Mechanical properties of rubberized concretes depend on the type and the content of utilized rubber. It was revealed that adding rubber particles to cement-based material provide a lower compressive strength [1,2,9-11]. The decrease in the compressive strength can be justified by the well-established fact that the compressive strength of concrete depends on the aggregates and on their volumetric proportion. The understanding of the relationship between the macroscopic mechanical behavior and the microstructural properties (such as volume fraction) is far from satisfactory. Some research had already been done on soft computing techniques mainly artificial neural networks to identify a model and control of its different components as: cement, fine aggregates, coarse aggregates, sand, admixtures, ground, crumb and chipped rubber. Artificial neural networks (ANN) are known as intelligent methods for modeling the behavior of physical phenomena. ANN takes data samples rather than entire data sets to arrive at solutions, which saves both time and money.

Artificial neural networks were developed to model the human brain. ANN is successfully used in the civil engineering applications which are suitable examining the complicated relations between variables.

Some researchers have used ANN for predicting compressive strength. Topçu et al. [12] constructed feed-forward models of ANN method. Authors applied ANN for predicting compressive strength of the waste crushed autoclaved aerated concrete. They concluded that the properties of waste 
autoclaved aerated concrete aggregates can be obtained by using ANN. Other studies have used ANN for modeling mechanical properties of rubberized concrete based on its design mix constituents as follows: cement, fly ash, sand, coarse aggregates, admixture and water-binder ratio. Topçu et al. [13] applied ANN for predicting compressive strength of waste rubber mortars. Their results showed that training and testing results are similar to the experimental results. Saridemir et al. [14] have used AAN for prediction of long-term effects of ground granulated blast furnace slag on compressive strength of concrete under wet curing conditions. Their results displayed that ANN have strong potential for prediction of long-term effects of ground granulated blast furnace slag. Gesoglu et al. [15] proposed the ANN for predicting compressive strength. Based on explicit model authors proposed ANN for the prediction of mechanical properties of rubberized concretes. In their study, authors have taken cement, silica fume, water, superplasticizer, coarse aggregates, fine aggregates, crumb rubber and tire chips separately.

On the other hand, some researchers have investigated the impact of water/cement ratio the mechanical properties such as compressive strength of rubberized concrete. Results show that compressive strength decreased with an increase in the water/cement ( $w / c)$ ratio. Guneyisi et al. [16] indicate that for lower $\mathrm{w} / \mathrm{c}$ ratio compressive strength is more important in plain concrete and with silica fume. For plain concrete compressive strength were about 54 and $76 \mathrm{GPa}$ at 0.60 and $0.4 \mathrm{w} / \mathrm{cm}$. With increasing rubber content to $50 \%$ of the total aggregate volume, the compressive strength reduced to about 7 and $10 \mathrm{GPa}$ for $w / \mathrm{cm}$ ratios of 0.60 and 0.40 , respectively. Uygunoglu et al. [17] have studied the effects of partial replacement of fine aggregates with scrap tire-rubber in self-consolidating mortar. Authors concluded that for a given rubber content, a lower w/c leads to a higher compressive strength. Test results indicate that for control mix the high value of compressive strength is obtained for lower w/c ratio. Note that many researchers used superplasticizers in mixes of rubcrete in order to reduce the water/cement ratio of the former rubcrete. On the one hand, the increase in the water/cement ratio increases the total porosity and the mechanical properties of rubberized concrete are closely related to its porosity and pore distribution. The existing literature related to rubberized concretes shows that the use of rubber increases the porosity of rubcrete if natural aggregate contain are partially replaced by rubber [18]. Thomas et al. [19] in their study have considered different water/cement ratio of $0.40,0.45,0.50$ and studied the variations of properties in different concrete mix where crumb rubber was replaced for natural fine aggregates from $0 \%$ to $20 \%$ in multiple of $2.5 \%$. The results indicate that the porosity values increases with increase in percentage of crumb rubber and water/cement ratio. On the other hand, the pore system in cement-based materials consists of four types of pores. These are gel pores which are directly related to shrinkage and creep, they do not influence the strength of concrete adversely through its porosity. Macropores due to deliberately entrained air, macropores due to inadequate compaction and capillary pores which are responsible for reduction in strength and elasticity. This latest category with the highest specific surface area of aggregate increases the pore configuration by increasing the pore size, porosity and the particle-size distribution. Capillary porosity of hardened cement paste depends on $w / c$ ratio. Water / cement ratio also governs the transition zone porosity in concrete [20]. Furthermore, porosity significantly affects the hardened characteristics of cement-based materials.

The aim of this paper is to use soft computing technique as artificial networks to develop a model that can predict with accuracy compressive strength. The model is built and valorized within three parameters that are: water/cement ratio, superplasticizer and granular squeleton. Furthermore, based on experimental data gathered from literature, a neural network technique is carried out to derive an explicit ANN formulation for the prediction of compressive strength as a function of three input parameters cited above where granular squeleton gathers fine aggregates, coarse aggregates, crumb rubber and tire chips. This ANN formulation conducted to model which has physical reality.

\section{Methodology}

Collecting and preparing sample data is the first step in designing ANN model. Considering that creation of a good neural network requires the existence of an accurate and comprehensive data-set, therefore, 112 different design mixes are collected from available literature $[15,21-24]$ on concrete containing rubber, summarized in Table 1 where $W / C, S P\left(\mathrm{~kg} / \mathrm{m}^{3}\right), G S\left(\mathrm{~kg} / \mathrm{m}^{3}\right), F c$ (MPa) designated water-cement ratio, superplasticizer, Granular Squeleton and compressive strength respectively. The constituent of design mixes used by authors are: cement, water, superplasticizer, coarse aggregates (gravel), fine aggregates (sand), crumb rubber $(0-4 \mathrm{~mm})$ and tire chips $(4-10 \mathrm{~mm})$. In order to study the impact of the water/cement ratio, the superplasticizer and granular squeleton in the values of the compressive strength of rubberized concrete, a test model is carried out to provide information about this mechanical characteristic.

A descriptive statistics analysis is carried out to provide information and effects of the parameters that are considered in this study (water-cement ratio, superplasticizer and granular squeleton) on compressive strength of the rubberized concrete. To allow the descriptive statistics analysis extend to the edges of modeling domain, it is ensured that extreme values (minimum and maximum values) of each constituent of total database are included in descriptive database as: maximum value, minimum value, mean and standard deviation of each constituent. Table 2 Shows the statistical parameters of the data used for statistics analyze. 
Table 1 Database used on modeling (Gesoglu et al, 2010 ; Gesoglu et Guneyisi, 2015; Nguyen, Toumi and Turatsinze, 2010; Ganjian et al 2009; Cuong ,2010)

\begin{tabular}{|c|c|c|c|c|c|c|c|c|c|c|c|c|c|c|}
\hline $\mathrm{N}^{\circ}$ & $\mathrm{W} / \mathrm{C}$ & SP & GS & $\mathrm{Fc}$ & $\mathrm{N}^{\circ}$ & $\mathrm{W} / \mathrm{C}$ & SP & GS & $\mathrm{Fc}$ & $\mathrm{N}^{\circ}$ & $\mathrm{W} / \mathrm{C}$ & SP & GS & $\mathrm{Fc}$ \\
\hline 1 & 0,42 & 13,50 & 1743,02 & 81,00 & 39 & 0,60 & 5,25 & 1487,1 & 16,20 & 77 & 0,40 & 5,40 & 1357,2 & 17,00 \\
\hline 2 & 0,44 & 13,50 & 1735,97 & 82,70 & 40 & 0,67 & 5,25 & 1477,9 & 20,10 & 78 & 0,47 & 3,25 & 1600 & 52,50 \\
\hline 3 & 0,47 & 13,50 & 1728,92 & 84,00 & 41 & 0,71 & 5,25 & 1473,3 & 21,20 & 79 & 0,47 & 3,25 & 1600 & 52,10 \\
\hline 4 & 0,60 & 5,25 & 1773,4 & 53,80 & 42 & 0,40 & 13,50 & 1185 & 10,50 & 80 & 0,47 & 3,25 & 1600 & 51,20 \\
\hline 5 & 0,63 & 5,25 & 1767,9 & 56,80 & 43 & 0,42 & 13,50 & 1180,2 & 11,20 & 81 & 0,47 & 3,25 & 1600 & 50,80 \\
\hline 6 & 0,67 & 5,25 & 1762,4 & 57,70 & 44 & 0,44 & 13,50 & 1175,4 & 11,60 & 82 & 0,47 & 3,25 & 1420 & 28,10 \\
\hline 7 & 0,71 & 5,25 & 1756,9 & 60,30 & 45 & 0,47 & 13,50 & 1170,8 & 11,70 & 83 & 0,47 & 3,25 & 1420 & 27,70 \\
\hline 8 & 0,40 & 13,50 & 1721,8 & 70,40 & 46 & 0,60 & 5,25 & 1200,8 & 7,10 & 84 & 0,47 & 3,25 & 1420 & 28,30 \\
\hline 9 & 0,44 & 13,50 & 1707,9 & 75,40 & 47 & 0,67 & 5,25 & 1193,4 & 8,10 & 85 & 0,47 & 3,25 & 1420 & 28,60 \\
\hline 10 & 0,47 & 13,50 & 1701 & 78,30 & 48 & 0,71 & 5,25 & 1189,7 & 8,40 & 86 & 0,47 & 3,25 & 1335 & 21,50 \\
\hline 11 & 0,60 & 5,25 & 1744,8 & 47,00 & 49 & 0,50 & 13,50 & 1721,88 & 85,77 & 87 & 0,47 & 3,25 & 1335 & 19,60 \\
\hline 12 & 0,63 & 5,25 & 1739,3 & 50,20 & 50 & 0,75 & 5,25 & 1751,5 & 59,70 & 88 & 0,47 & 3,25 & 1335 & 19,10 \\
\hline 13 & 0,67 & 5,25 & 1734 & 52,50 & 51 & 0,50 & 13,50 & 1694,1 & 79,10 & 89 & 0,50 & 1,52 & 1785 & 32,00 \\
\hline 14 & 0,71 & 5,25 & 1728,7 & 55,40 & 52 & 0,50 & 13,50 & 1666,3 & 69,40 & 90 & 0,50 & 1,52 & 1788,4 & 33,00 \\
\hline 15 & 0,42 & 13,50 & 1686,8 & 67,80 & 53 & 0,75 & 5,25 & 1694,9 & 51,30 & 91 & 0,50 & 1,52 & 1788,5 & 30,00 \\
\hline 16 & 0,44 & 13,50 & 1679,9 & 68,20 & 54 & 0,50 & 13,50 & 1610,7 & 61,70 & 92 & 0,50 & 1,52 & 1790 & 25,00 \\
\hline 17 & 0,47 & 13,50 & 1673,1 & 68,00 & 55 & 0,75 & 5,25 & 1638,3 & 41,20 & 93 & 0,50 & 1,52 & 1804 & 30,00 \\
\hline 18 & 0,60 & 5,25 & 1716,1 & 41,50 & 56 & 0,50 & 13,50 & 1555,1 & 47,00 & 94 & 0,50 & 1,52 & 1813 & 27,00 \\
\hline 19 & 0,63 & 5,25 & 1710,8 & 43,10 & 57 & 0,75 & 5,25 & 1581,8 & 34,20 & 95 & 0,50 & 1,52 & 1823 & 20,00 \\
\hline 20 & 0,71 & 5,25 & 1700,2 & 49,30 & 58 & 0,50 & 13,50 & 1443,9 & 31,80 & 96 & 0,47 & 3,03 & 1839,9 & 63,70 \\
\hline 21 & 0,40 & 13,50 & 1637 & 50,70 & 59 & 0,75 & 5,25 & 1468,7 & 23,10 & 97 & 0,47 & 3,29 & 1743,8 & 39,50 \\
\hline 22 & 0,42 & 13,50 & 1630,5 & 55,30 & 60 & 0,75 & 5,25 & 1186 & 8,60 & 98 & 0,47 & 3,61 & 1695,7 & 26,30 \\
\hline 23 & 0,44 & 13,50 & 1659,9 & 56,30 & 61 & 0,40 & 1,80 & 1678,6 & 53,50 & 99 & 0,47 & 3,99 & 1647,7 & 17,90 \\
\hline 24 & 0,47 & 13,50 & 1617,3 & 55,60 & 62 & 0,40 & 2,25 & 1652,7 & 49,70 & 100 & 0,40 & 13,50 & 1750,02 & 75,80 \\
\hline 25 & 0,60 & 5,25 & 1658,9 & 31,80 & 63 & 0,40 & 2,70 & 1626,8 & 44,50 & 101 & 0,42 & 13,50 & 1714,80 & 72,50 \\
\hline 26 & 0,67 & 5,25 & 1648,6 & 37,60 & 64 & 0,40 & 3,15 & 1601 & 40,70 & 102 & 0,40 & 13,50 & 1693,50 & 62,80 \\
\hline 27 & 0,71 & 5,25 & 1643,6 & 41,30 & 65 & 0,40 & 3,60 & 1575,1 & 35,30 & 103 & 0,67 & 5,25 & 1705,60 & 46,10 \\
\hline 28 & 0,40 & 13,50 & 1580,6 & 40,30 & 66 & 0,40 & 4,05 & 1549,2 & 34,34 & 104 & 0,63 & 5,25 & 1653,80 & 35,80 \\
\hline 29 & 0,42 & 13,50 & 1574,3 & 44,50 & 67 & 0,40 & 4,50 & 1523,3 & 27,00 & 105 & 0,60 & 5,25 & 1601,50 & 24,30 \\
\hline 30 & 0,44 & 13,50 & 1567,7 & 45,10 & 68 & 0,40 & 2,70 & 1623,2 & 43,77 & 106 & 0,63 & 5,25 & 1482,40 & 18,20 \\
\hline 31 & 0,47 & 13,50 & 1561,5 & 46,40 & 69 & 0,40 & 3,15 & 1595,6 & 37,90 & 107 & 0,63 & 5,25 & 1197,10 & 7,20 \\
\hline 32 & 0,63 & 5,25 & 1596,6 & 28,80 & 70 & 0,40 & 3,60 & 1567,9 & 33,75 & 108 & 0,75 & 5,25 & 1723,30 & 56,40 \\
\hline 33 & 0,67 & 5,25 & 1591,7 & 31,40 & 71 & 0,40 & 4,05 & 1540,3 & 31,00 & 109 & 0,50 & 13,50 & 1166,00 & 11,70 \\
\hline 34 & 0,71 & 5,25 & 1586,8 & 32,80 & 72 & 0,40 & 4,50 & 1512,5 & 25,00 & 110 & 0,40 & 2,25 & 1651,00 & 47,20 \\
\hline 35 & 0,40 & 13,50 & 1467,6 & 26,40 & 73 & 0,40 & 3,15 & 1625,1 & 42,20 & 111 & 0,40 & 4,95 & 1410,90 & 19,40 \\
\hline 36 & 0,42 & 13,50 & 1461,7 & 29,60 & 74 & 0,40 & 3,60 & 1571,4 & 36,13 & 112 & 0,47 & 3,25 & 1335,00 & 20,20 \\
\hline 37 & 0,44 & 13,50 & 1455,8 & 30,50 & 75 & 0,40 & 3,55 & 1518 & 32,43 & & & & & \\
\hline 38 & 0,47 & 13,50 & 1449,8 & 31,80 & 76 & 0,40 & 4,50 & 1464,4 & 26,10 & & & & & \\
\hline
\end{tabular}

Table 2 Statistical parameters of training

\begin{tabular}{lcccc}
\hline & Min & Max & Mean & St.Dev \\
\hline W/C & 0,40 & 0,75 & 0,5156 & 0,1138 \\
$\mathrm{SP}\left(\mathrm{kg} / \mathrm{m}^{3}\right)$ & 1,52 & 13,50 & 7,0291 & 4,5102 \\
$\mathrm{GS}\left(\mathrm{kg} / \mathrm{m}^{3}\right)$ & 1166,00 & 1839,90 & 1579,7 & 171,9352 \\
$\mathrm{Fc}(\mathrm{GPa})$ & 7,10 & 85,77 & 40,2713 & 19,5876 \\
\hline
\end{tabular}

2.1 Preparing training, validation and test data sets

Usually, the complete set containing all available data sets of the system behavior is divided into three subsets, which are called training subset, validation subset and test subset. The training subset, composed of $70 \%$ of random samples from the complete database, will be essentially in the learning process. On the other hand, the validation subset, which is composed of $15 \%$ from the complete data set, is used to verify if the network capabilities of generalizing solutions are within acceptable levels, thus allowing the test subset, which is composed of $15 \%$ from the complete data set, is used to evaluate the prediction performance of the model.

The training of the network is done by Levenberg Marquardt algorithm. This algorithm is used for adjusting the weights and training efficiency. During the training process, the weights 

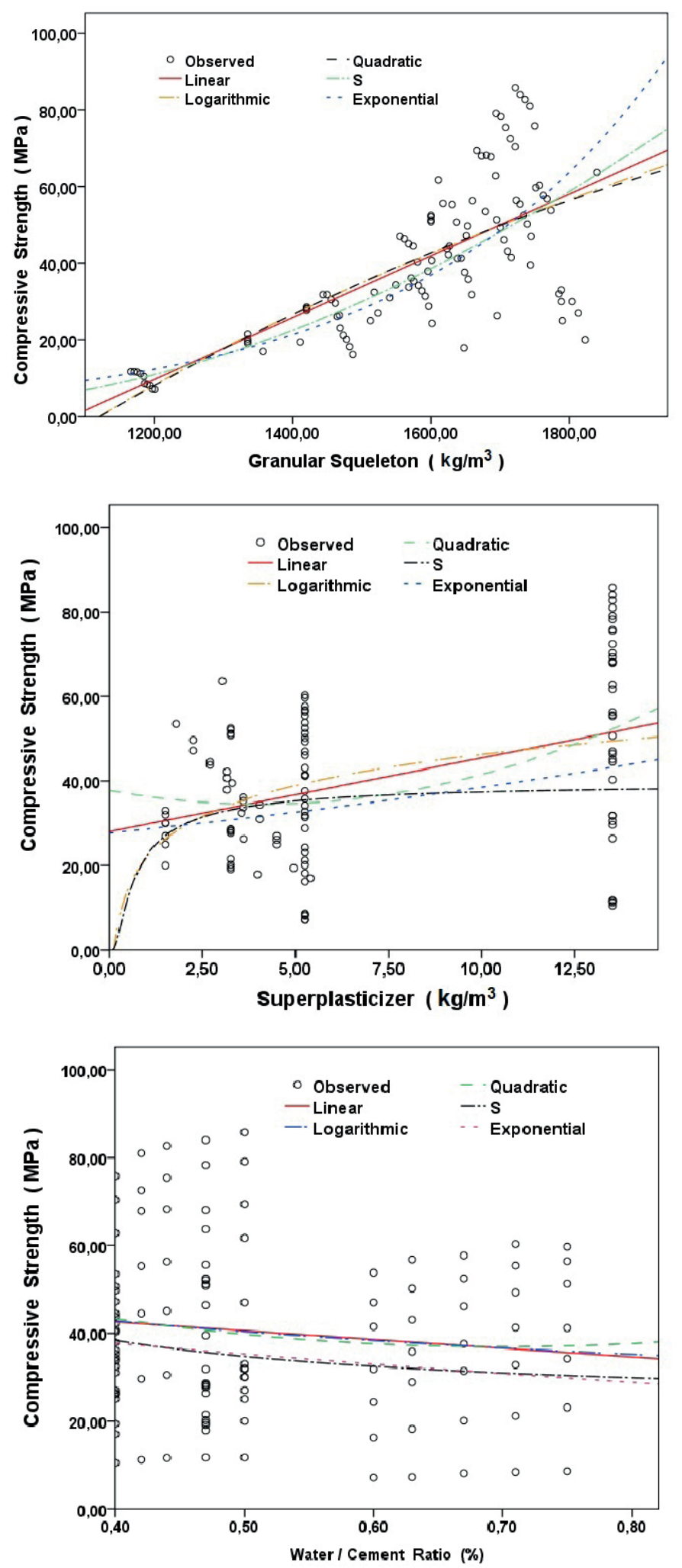

Fig. 1 (a) Variation of compressive strength vs granular squeleton (b) Variation of compressive strength vs superplasticizer (c) Variation of compressive strength vs $\mathrm{W} / \mathrm{C}$ ratio.

are adjusted in order to make the outputs (predicted) close to the target (measured) outputs of the network. The sum of the modified weight input and bias are then modified by a tan-sigmoid transfer function. Similarly, output from the hidden layer is modified by an appropriate weight and the sum of modified output signal is again modified by a tan-sigmoid transfer function. After completion of the training process, validation of neural network is done. Neural network is tested to determine the performance of the ANN model for predicting performance parameters.

The objective of the algorithm is to minimize the mean sum of squared error for the entire experimental data. To allow the training data-set extend to the edges of modeling domain, it is ensured that extreme value (minimum and maximum values) of each constituent of total data-set are included in training data-set, validation and test data sets Table 2 .

After that, a bivariate correlation procedure computes Kendall's taub-b with the significance level is used. Correlations measure how variables or rank orders are related. A bivariate correlations procedure computes the pairwise associations for set variables (compressive strength, water/cement ratio, granular squeleton, superplasticizer) and displays the results in a matrix. Subsequent to this step, curves estimation of compressive strength as a dependent variable function of others independent variables (the above parameters) are established. Scatterplot representations (Fig. 1) show the curve estimation of compressive strength versus the parameters cited above.

The Curve Estimation procedure produces curve estimation regression statistics and produce related plots for three (03) different curve estimation models. A separate model is produced for each dependent variable. Curve estimation is most appropriate when the relationship between the dependent variable (compressive strength $F_{c}$ ) and the independent variable (water/cement ratio, granular squeleton and superplasticizer) is not necessarily linear. $R$-squared is statistical parameter that estimates the proportion of the total variation in the series that is explained by the model. If the $R$ squared $\left(R^{2}\right)$ change associated with a variable is large, that means that the variable is a good predictor of the dependent variable. For each model: $R^{2}$, is calculated for different models: linear, logarithmic, quadratic, S-curve, and exponential. Fig .1 shows that the curve fit chart gives a quick visual assessment of the fit of each model to the observed values. From the plot (a), it appears that the Exponential model better follows the shape of the data. In particular, the linear model seems to overestimate compressive strength for cases with medium values of granular squeleton $\left(1250 \mathrm{~kg} / \mathrm{m}^{3}<\mathrm{GS}<1650 \mathrm{~kg} / \mathrm{m}^{3}\right)$. From the plot $(b)$, it appears that the Quadratic model better follows the shape of the data. From the plot (c), it appears that the Exponential model better follows the shape of the experimental data. The results of $R$ square $\left(R^{2}\right)$ are summarized in Table 3 .

Table 3 Estimation of $R$ square vs the input data with different curves estimation regression models.

\begin{tabular}{lccc}
\hline Equation & \multicolumn{3}{c}{$R^{2}$} \\
\hline Exponential & 0,654 & 0,066 & 0,018 \\
Quadratic & 0,503 & 0,173 & 0,015 \\
Logarithmic & 0,501 & 0,132 & 0,014 \\
Linear & 0,500 & 0,161 & 0,014 \\
\hline
\end{tabular}




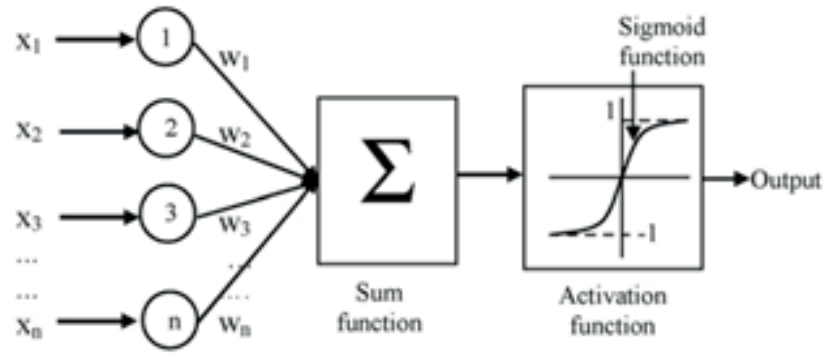

Fig. 2 Simple Model Neuron

\subsection{Preprocessing of data}

Data pre-processing is an important and critical step in the data process. In this step, the knowledge of database reduces the complexity of the data and offers better conditions. Pre-processing has a huge impact in the success of data project. Analyzing data that has not been carefully separated for such problems can produce confusing results. If there is inappropriate information present, then knowledge discovery becomes very difficult during the training process. Three data preprocessing procedures are conducted to train the ANN model more efficiently that are: (1) solve the problem of missing data, (2) normalize data and (3) randomize data. Through this step, we used decimal scaling and data normalization to map the data to uniform scale. Scaling of input are ranged between $[-1 ;+1]$ greatly improves the learning speed as these values fall in the region of sigmoid function.

\subsection{Artificial neural network architecture and training parameters}

Artificial neural network (ANN) is a type of artificial intelligence technique that mimics the behavior of the human brain [14]. The concept of neural networks was introduced by McCulloch et al. [25]. They developed the first neural network model for the first time and developed a cell model as in Figure $2[26,27]$.

The neural network approach is promising tool for problems where the solution algorithm is unknown or so complicated that is impossible to solve the problem directly. It has been receiving an increasing attention and may be used to develop the predictive models. ANN modeling is nonlinear information processing paradigm that simulated the behavior of the human brain and nervous system. A neural network is massively parallel distributed processor made up of simple processing units that have a natural tendency for storing experimental knowledge and making it available for us. The main component of neural network is the neuron. A neural network is a network of many simple processes, which are named nodes or neurons. Each neuron receives weighted inputs from other neurons and communicates its outputs to other neurons by using an activation function.

Thus, information is represented by massive cross-weighted interconnections. Neural networks might be single-or multi layered. Three important processes must be considered in constructing a successful artificial neural network: Training, validation and testing. The connection weights of the neural network are adjusted through the training process, while the training effect is referred to as learning. Training of neural networks usually involves modifying connection weights by means of a learning rule. The learning process is done by giving weights and biases computes from a set of training data by adjusting the weights according to a certain condition.

Then, other validation data are used to check the generalization. In general, initial weights and biases joining nodes of an input layer, hidden layers and an output layer are commonly assigned randomly. The weights and biases are changed for the output of networks to match required data values. As input data are passed through hidden layers, sigmoidal activation functions are generally used. During the training procedure, the data are selected uniformly. A specific pass is completed when all data sets have been processed. Generally several passes are required to attain a desired level of estimation accuracy. Consequently, learning corresponds to determining the weights and biases associated with the connections in the networks training until the network stabilize. Initial estimated weight values are progressively corrected during a training process that compares predicted outputs to known outputs, and back propagates any errors to determine the appropriate weight adjustments necessary to minimize the errors.

Sum function is a function that calculates the effect of inputs and weights.This function calculates the net input that comes to a cell $[28,29]$.

The weighted sum of inputs components can be calculated as in Eq. (1):

$$
(\text { net })_{j}=\sum_{i=1}^{n} w_{i j} * x_{i}+b
$$

where $(n e t)_{j}$ is the weighted sum of the $j$ neuron for the input received from the preceding layer, $x_{i}$ is the output of the i neuron in the preceding layer. $\mathrm{b}$ a fix value as internal addition. Sum function is sent to a preselected transfer function, called an activation function. The filtered output (Output) $)_{j}$ (compressive strength) is generated in the outgoing end of the artificial neuron $(j)$ through the mapping of the transfer function. Usually, among the types of transfer functions, the sigmoid transfer functions are used to solve problems [30]. The function considered in our work is the hyperbolic tangent function (Eq. 2). She offers more accurate predictions. The behavior of an ANN depends on both the weights and transfer function that is specified for the units. The transfer function can be represented by the following equation:

$$
(\text { Output })_{j}=\left(e^{\alpha(n e t)_{j}}-e^{-\alpha(n e t)_{j}}\right) /\left(e^{\alpha(n e t)_{j}}+e^{-\alpha(n e t)_{j}}\right) .
$$

where: $\alpha$ is a constant used to control the slope of the semi-linear region and (Output) is compressive strength. This function transforms the interval $[-\infty ;+\infty]$ to $[-1 ;+1]$. 
Once the training phase of the model has been successfully accomplished, the network performance is verified by presenting independent validation datasets to the ANN. This process is calling "validation".

Different ANN architectures were tried using this code and the appropriate model structure was determined. The selected architecture was 3-3-1-1.

The values of parameters used in the research are as follows:

- Number of input Layer units $=3$ (That means there are 3 nodes in the input layer corresponding to three parameter namely: Water-Cement ratio $(W / C)$, superplasticizer $(S P)$ and Granular squeleton ( $G S$ : Association of coarse aggregates, fine aggregates, crumb rubber and tire chips))

- Number of hidden layer $=3$

- Number of output layer unit =2

- Number of first output layer units $=3$

- Number of second output layer unit $=1$

- Learning rate $=0.9$

- Error after learning $=0.001$

In this study, the artificial neural network model is divided into three parts, called layers, which are known as: Input layer, hidden layer and output layer. Input layer receive dataset. Hidden layer are composed of neurons which are extracting patterns associated with the process being analyzed. Output layer is composed of neuron, which result (compressive strength) is from the processing performed by the hidden layers.

Note that in this study the key parameters used in model are water-cement ratio and granular squeleton.

\subsection{Performance evaluation of trained models}

The performance of a neural network depends on the architecture and settings parameters. In this study, statistical analysis involving the mean square error (MSE) (3), mean absolute error (MAE) (4) and coefficient of correlation (R) (5) were conducted to evaluate the performance of model. Lower MSE indicates more accurate estimation. MSE provides information on the short term performance which is measure of the variation of predicted values around the measured data.

$$
\begin{gathered}
M S E=\left(\sum_{i=1}^{N}\left(O_{i}-P_{i}\right)^{2}\right) / N \\
M A E=\left(\sum_{i=1}^{N}\left(\left|O_{i}-P_{i}\right|\right)\right) / N \\
R=\frac{\sum_{i=1}^{N}\left(O_{i}-M_{i}\right)\left(P_{i}-N_{i}\right)}{\sqrt{\sum_{i=1}^{N}\left(O_{i}-M_{i}\right)^{2} \sum_{i=1}^{N}\left(P_{i}-N_{i}\right)^{2}}}
\end{gathered}
$$

where $O_{i}, P_{i}$ and $M_{i}$ denote the observed or target values, ANN predicted values and the mean of $O_{i}$ respectively. $N$ represents the total number of data.
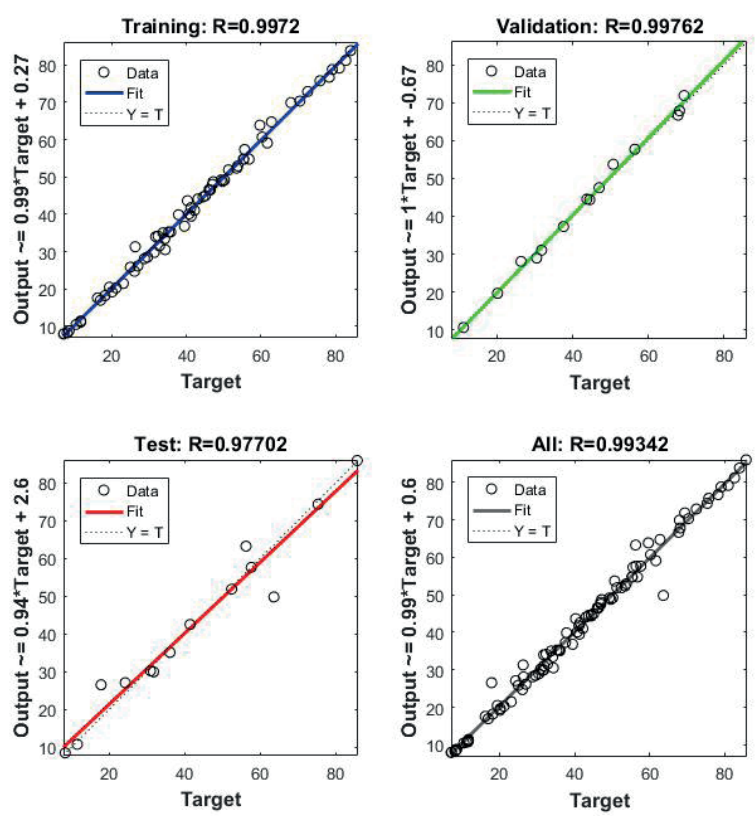

Fig. 3 Training data, validation, test and all results of ANN

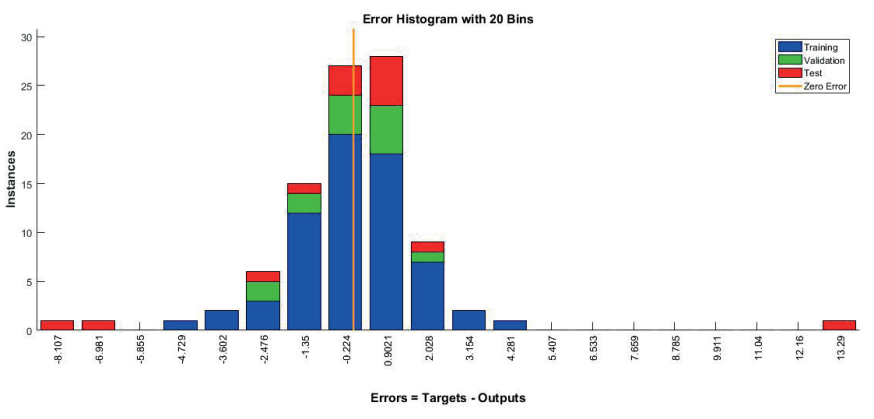

Fig. 4 The Instances vs Errors results between targets and outputs

\section{Results}

The neural network architecture selected for the modeling compressive strength of rubberized concrete (3-3-1-1) is trained. The regression plot showing the prediction of trained, validation and test of ANN model are exhibited in Fig. 3. The compressive strength reached both from training and experiments were obtained as seen in Fig. 3.a. The compressive strength reached both from validation and from experiments were obtained as seen in Fig. 3.b. The model subsequent to training and validation is testing. Furthermore compressive strength results obtained from both test and experimental data are plotted in Fig. 3.c. All values of training, validation and testing are plotted in Fig. $3 \mathrm{~d}$. Correlation coefficient for training, validation and testing are: $99.72 \%, 99.76 \%$, and $97.70 \%$ respectively.

Also, the errors percentage rates of compressive strength reached from training, testing and validation in ANN model are given in Fig. 4.

The statistical values for compressive strength found from training, validation and testing in ANN model as correlation coefficient (R), Mean Squared Error (MSE) and Mean Absolute error (MAE) are also given in Table 4.

The predicted compressive strength is generated. Eq. 6-10. 
Table 4 Statistical values of proposed ANN model,

\begin{tabular}{lccc}
\hline \multirow{2}{*}{ Equation } & \multicolumn{3}{c}{ Compressive Strength } \\
\hline Samples & Training set & Validation & Testing set \\
R & 78 & 17 & 17 \\
MAE & 0,9972 & 0,9976 & 0,9770 \\
MSE & 1,1336 & 1,0674 & 2,8333 \\
\hline
\end{tabular}

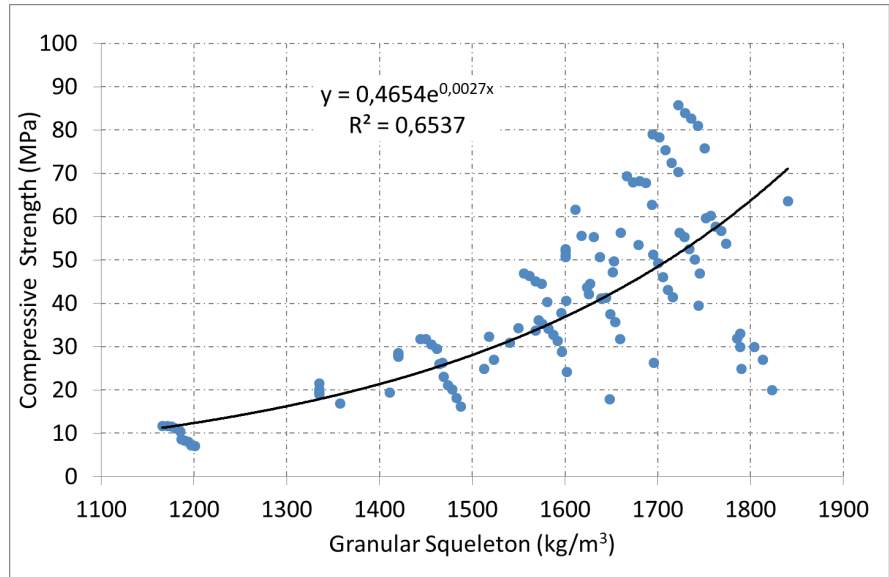

Fig. 5 Compressive Strength vs Granular Squeleton

$$
\text { Output }=b_{2}+L W * \tanh \left(b_{1}+I W * x\right)
$$

Where:

$\mathrm{x}$ : input value

$$
\begin{aligned}
& b_{1}=\left(\begin{array}{c}
-27.3414 \\
3.8832 \\
1.1677
\end{array}\right) \\
& b_{2}=1.9177 \\
& I W=\left(\begin{array}{ccc}
-4.0478 & 20.3826 & 3.5032 \\
1.9852 & 2.7750 & 0.2251 \\
-0.2314 & -0.4627 & -0.9098
\end{array}\right) \\
& L W=\left(\begin{array}{lll}
-0.1832 & -0.5474 & -2.6069
\end{array}\right)
\end{aligned}
$$

\section{Discussion}

Analyzing the results, it can be seen that the statistical values coefficient of correlation $(R)$, mean absolute error (MAE) and mean square error (MSE) from training set in ANN model were found as $99.72 \%, 1.1336$ and 2.3100 respectively, these values were found in testing and validation as $99.76 \%, 1.0674$, 1.8102 and $97.70 \%, 2.8333,23.7079$ respectively.

The errors for the values used for training, validation and testing range between -8.107 and 13.29 for all the input values. Furthermore, the values used for training, validation and testing data that have an error between -2.476 and 2.028 are very important than the others values as seen in Fig. 4.

In our model, we have used three inputs that are water/cement ratio, superplasticizer and granular squeleton which included seven data gathers: water, cement, superplasticizer, fine aggregate, coarse aggregate, fine rubber and crumb rubber. The model gives a higher coefficient of correlation $(R)$ with lower MAE and MSE. However, the model gives good results in the validation and testing set.

With an increase of rubber particles, granular squeleton decreases as seen in Fig. 5. From the low errors between the target and output values shown in Fig. 4, it clearly appears that the predicted values decrease with granular squeleton. Itcan be noticedthat there exist a good correlation in the variation of experimental data and predicted values of compressive strength.

\section{Conclusions}

To wrap, a prediction model was carried out in artificial neural networks in order to predict of rubberized concrete on compressive strength. The model was trained with important parameters that are water/cement ratio, granular squeleton and output experimental data: compressive strength.

Using only the input data in trained model the compressive strength values of rubberized concrete were found for testing the model. Error technique has been employed for determining the compressive strength. The values are very closer to the experimental data obtained from training, testing and validation for artificial neural networks. The model gives good results in the validation and testing set with a higher coefficient of correlation $(R)$, lower MAE and MSE. The statistics values calculated for comparing experimental data with artificial neural networks model have shown good prediction for the ANN constructed model.

As a result, compressive strength values of the rubberized concrete can be predicted in ANN without attempting any experiments.

\section{References}

[1] Elchalakani, M. "High strength rubberized concrete containing silica fume for the construction of sustainable road side barriers". Structures, 1(1), pp. 20-38. 2015.

https://doi.org/10.1016/j.istruc.2014.06.001

[2] Youssf, O., Elgawady, M. A., Mills, J. E., Ma, X. "An experimental investigation of crumb rubber concrete confined by fiber reinforced polymer tubes". Construction and Building Materials, 53, pp. 522-532. 2014. https://doi.org/10.1016/j.conbuildmat.2013.12.007

[3] Gupta, T., Chaudhary, S., Sharma, R. K. "Assessment of mechanical and durability properties of concrete containing waste rubber tire as fine aggregate". Construction and Building Materials, 73, pp. 562-574. 2014. https://doi.org/10.1016/j.conbuildmat.2014.09.102

[4] Gesoglu, M., Guneyisi, E., Khoshnaw, G., Ipek, S. "Investigating properties of pervious concretes containing waste tire rubbers". Construction and Building Materials, 63, pp. 206-213. 2014.

https://doi.org/10.1016/j.conbuildmat.2014.04.046

[5] Duplan, F., Abou-chakra, A., Turatsinze, A., Escadeillas, G., Brule, S. Masse, F. "Prediction of modulus of elasticity based on micromechanics theory and application to low-strength mortars". Construction and Building Materials, 50, pp. 437-447. 2014.

https://doi.org/10.1016/j.conbuildmat.2013.09.051 
[6] Rahman, M. M., Usman, M., Al-Gharib, A. A. "Fundamental properties of rubber modified self-compacting concrete (RMSCC)". Construction and Building Materials, 36, pp. 630-637. 2012.

https://oi.org/10.1016/j.conbuildmat.2012.04.116

[7] Bharati, R.,Ganesan, N., Shashikala, A. P. "Engineering properties of self-compacting rubberized concrete". Journal of Reinforced Plastics \& Composites, 30(23), pp. 1923-1930. 2011.

https://doi.org/10.1177/0731684411431356

[8] Rozas, F., Castillo, A., Martinez, I., Castellote, M. "Guidelines for assessing the valorization of waste into cementitious materials: dredged sediment for production of self compacting concrete". Materiales de Construcción, 65(319), e057, 2015.

https://doi.org/10.3989/mc.2015.10613

[9] Medine, M., Trouzine, H., De Aguiar, J. B., Asroun, A. "Durability of five years aged lightweight concretes containing rubber aggregates", $P e$ riodica Polytechnica Civil Engineering, 62(2), pp. 386-397. 2018. https://doi.org/10.3311/PPci.11363

[10] Belabdelouahab, F., Trouzine, H., Hellal, H., Rahali, B., Ould Kaci, S., Medine, M. "Comparative analysis of estimated young's modulus of rubberized mortar and concrete". International Journal of Civil Engineering, 16(2), pp. 243-253. 2018. https://doi.org/10.1007/s40999-016-0119-x

[11] Medine, M., Trouzine, H., De Aguiar, J. B. "Fresh state properties of concrete incorporating scrap tire rubber". Periodica Polytechnica Civil Engineering, 60(4), pp. 611-617. 2016. https://doi.org/10.3311/PPci.8727

[12] Topçu, I. B., Sardimir, M. "Prediction of properties of waste AAC aggregate concrete using artificial neural network Computational". Computational Materials Science, 41(1), pp.117-125. 2007. https://doi.org/10.1016/j.commatsci.2007.03.010

[13] Topçu, I. B., Sardimir, M. "Prediction of rubberized mortar properties using artificial neural network and fuzzy logic". Journal of Materials Processing Technology, 199(1-3), pp. 108-118. 2008. https://doi.org/10.1016/j.jmatprotec.2007.08.042

[14] Saridemir, M., Topçu, I. B.,Özcan, F., Severcan, M. H. "Prediction of long-term effects of GGBFS on compressive strength of concrete by artificial neural networks and fuzzy logic". Construction and Building Materials, 23(3), pp. 1279-1286.2009.

https://doi.org/10.1016/j.conbuildmat.2008.07.021

[15] Gesoglu, M., Guneyisi, E., Özturan, T., Özbay, .E. "Modeling the mechanical properties of rubberized concretes by neural network and genetic programming". Materials and structures, 43, pp. 31-45. 2010. https://doi.org/10.1617/s11527-009-9468-0

[16] Güneyisi, E., Gesoglu, M., Özturan, T. "Properties of rubberized concretes containing silica fume". Cement and Concrete Research, 34(12), pp. 2309-2317. 2004.

https://doi.org/10.1016/j.cemconres.2004.04.005

[17] Uygunoglu, T., Topçu, I. B. "The role of scrap rubber particles on the drying shrinkage and mechanical properties of self-consolidating mortars". Construction and Building Materials, 24(7), pp. 1141-1150. 2010. https://doi.org/10.1016/j.conbuildmat.2009.12.027

[18] Turatsinze, A., Garros, M. "On the modulus of elasticity and strain capacity of self-compacting concrete incorporating rubber aggregates". Resources, Conservation and Recycling, 52(10), pp. 1209-1215. 2008. https://doi.org/10.1016/j.resconrec.2008.06.012

[19] Thomas, B. S., Gupta, R. C. "Long term behaviour of cement concrete containing discarded tire rubber". Journal of Cleaner Production, 102, pp. 78-87. 2015. https://doi.org/10.1016/j.jclepro.2015.04.072

[20] Soroka, I. "Portland Cement Paste and Concrete". Macmillan, London, UK, 1979.
[21] Gesoglu, M., Güneyisi, E., Hansu, O., Ipak, S., Asaad, D. S. "Influence of waste rubber utilization on the fracture and steel-concrete bond strength properties of concrete". Construction and Building Materials, 101, Part 1. pp. 1113-1121. 2015.

https://doi.org/10.1016/j.conbuildmat.2015.10.030

[22] Nguyen, T. H., Toumi, A., Turatsinze, A. "Mechanical properties of steel fibre reinforced and rubberized cement-based mortars". Materials \& Design, 31(1), pp. 641-647. 2010.

https://doi.org/10.1016/j.matdes.2009.05.006

[23] Ho, A. C. "Optimisation de la composition et caractérisation d'un béton incorporant des granulats issus du broyage de pneus usagés: application aux éléments de grande surface". Thesis, INSA Toulouse. 2010.

[24] Ganjian, E., Khorami, M., Mahsoudi, A. A. "Scrap-tyre replacement for aggregate and filler in concrete". Construction and Building Materials, 23(5), pp. 1828-1836. 2009.

https://doi.org/10.1016/j.conbuildmat.2008.09.020

[25] McCulloch, W., Pitts, W. "A logical calculus of the ideas immanent in nervous activity". The Bulletin of Mathematical Biophysics, 5(4), pp. 115-133. 1943. https://doi.org/10.1007/BF02478259

[26] Arbib, M. A. "The Handbook of Brain Theory and neural networks". MIT Press, Cambridge, MA. 1995.

[27] Mukherjee, A., Biswas, S. N. "Artificial neural networks in prediction of mechanical behavior of concrete at high temperature". Nuclear Engineering and Design, 178(1), pp. 1-11.1997. https://doi.org/10.1016/S0029-5493(97)00152-0

[28] Öztas, A., Pala, M. E., Özbay, E., Kanca, E., Çag־lar, N., Bhatti, M. A. "Predicting the compressive strength and slump of high strength concrete using neural network". Construction and Building Materials, 20(9), pp. 769-775. 2006.

https://doi.org/10.1016/j.conbuildmat.2005.01.054

[29] Pala, M., Özbay, E., Öztas, A., Yuce, M. I. "Appraisal of long-term effects of fly and silica fume on compressive strength of concrete by neural networks". Construction and Building Materials, 21(2), pp. 384-394. 2007. https://doi.org/10.1016/j.conbuildmat.2005.08.009

[30] Uysal, M.,Tanyildizi, H. "Estimation of compressive strength of selfcompacting concrete containing polypropylene fiber and mineral additives exposed to high temperature using artificial neural network". Construction and Building Materials, 27(1), pp. 404-414. 2012. https://doi.org/10.1016/j.conbuildmat.2011.07.028 